\title{
Exercise training complementary to specialised early intervention in patients with first-episode psychosis: a feasibility randomised trial
}

\author{
Julie Midtgaard ( $\nabla$ julie.midtgaard.klausen@regionh.dk) \\ Rigshospitalet https://orcid.org/0000-0003-2381-2127 \\ Helle Schnor \\ Mental Health Centre Glostrup \\ Eik Dybboe Bjerre \\ Rigshospitalet \\ Tobias Jespersen \\ Mental Health Centre Glostrup \\ Nina Jelsøe \\ University of Copenhagen \\ Nanna Frølund \\ University of Copenhagen \\ Søren Seier \\ University of Copenhagen \\ Jacob Willum Rønbøg \\ University of Copenhagen \\ Nikolai Baastrup Nordsborg \\ University of Copenhagen \\ Bjørn Ebdrup \\ University of Copenhagen
}

Research

Keywords: Exercise training, Feasibility, First-episode psychosis, randomized trial

Posted Date: February 10th, 2021

DOI: https://doi.org/10.21203/rs.3.rs-203226/v1

License: (c) (i) This work is licensed under a Creative Commons Attribution 4.0 International License. Read Full License

Version of Record: A version of this preprint was published at Pilot and Feasibility Studies on August 19th, 2021. See the published version at https://doi.org/10.1186/s40814-021-00900-5. 


\section{Abstract}

\section{Background}

To examine feasibility of trial processes and group-based, structured exercise training in patients with first-episode psychosis (FEP).

Methods

Twenty-five patients with FEP took part in a two-arm randomised feasibility trial. Patients were individually randomised (1:1) via a computer-generated randomisation sequence and allocated to either an exercise intervention group (INT) or a control group (CON). Patients allocated to INT completed a physical exercise training programme at moderate-to-vigorous intensity, one hour three times weekly for 8 weeks. CON patients were encouraged to continue their usual level of activity and were offered the training programme after 8 weeks. Primary outcomes included screening rate, recruitment rate, retention rate, adherence, adverse events, and heart rate response during training. Secondary outcomes included cardiovascular health $\left(\mathrm{VO}_{2 \mathrm{max}}\right.$, resting heart rate, blood pressure), body composition (muscle mass, fat percentage), muscle strength (sit-to-stand, grip strength, jump height), and balance.

Results

Recruitment lasted 6 weeks and 86 out of 324 patients (27\%) were screened, 71 of whom (83\%) were deemed eligible. Twenty-five (35\%) accepted inclusion (mean age 25.5; mean body mass index 25.1) and were subsequently randomised (INT $=13 ; \mathrm{CON}=12$ ). Retention of patients was $76 \%$ and $52 \%$ at the 8 -week and 16 -week follow-up, respectively. Attendance was $43 \%$ (min. $9 \%$, max. $96 \%$ ). No significant changes were observed between groups in secondary physiological outcome measures.

\section{Conclusions}

Feasibility was challenged by limited recruitment and retention rates, suggesting that modifications are required if a large-scale randomised controlled trial is to be conducted. Recommendations for modifications are presented and discussed.

Trial registration

clinicaltrials.gov, NCT03409393 ('Retrospectively registered')

\section{Background}

Schizophrenia is a severe psychiatric disorder characterised by hallucinations or delusions and experiences that alter perception, thoughts, emotionality, and behaviour. The clinical symptoms usually manifest in early adult life $(1,2)$ and many patients experience persistent difficulties. Previous research indicates that specialised interventions that take place soon after the onset of the first episode of psychosis are associated with reduced symptoms and improved overall functioning. Consequently, specialised early intervention teams constitute standard treatment for first-episode psychosis in many developed countries (3-5). Concurrent with improved care and outcomes for patients with schizophrenia, prevention of impaired physical health and reduction in premature mortality of patients with schizophrenia is being increasingly acknowledged. Patients with schizophrenia have a four-fold higher prevalence of metabolic syndrome, and a two-tothree-fold higher risk of cardiovascular diseases compared to the general population (6) contributing to a premature mortality of 15-20 years observed in people with schizophrenia (7-9), and an increasing mortality gap (10).

An international team of researchers, clinicians, and key stakeholders (i.e. The Lancet Psychiatry Commission), recently pointed to physical activity as one key modifiable factor of importance to protecting physical health in people with mental illness (11). A 2015 review by Firth et al. (12) suggested that exercise can improve cardiometabolic risk factors, functional disability, psychiatric symptoms, co-morbid disorders, and neurocognition in schizophrenia. However, the quality of the included studies was low and mainly involved patients with established schizophrenia (i.e. median illness duration was 10 years), leaving limited potential for preventing development of cardiometabolic comorbidity $(12,13)$.

Treatment of schizophrenia by means of antipsychotic therapy is widely associated with weight gain and metabolic changes that may occur already within weeks after initiation of exposure (14-16). For this reason, early psychosis could be the optimal phase for introducing exercise to prevent or mitigate comorbid metabolic abnormalities and physical disorders (12). However, to our knowledge, only few previous studies (17-19) have explored exercise as primary/dominating intervention module in early psychosis. While the findings are promising, including some improvements in cardiorespiratory fitness and metabolic outcomes, the studies are plagued by methodological limitations, including lack of a standardised experimental design. 
Against this background we developed a randomised controlled trial intended to determine the feasibility of a physical exercise training programme in young adults with first-episode psychosis. Specifically, we aimed to establish screening rate, recruitment rate, retention rate, adherence, adverse events, and heart rate response during the intervention. Furthermore, we wished to explore potential physiological changes when compared to treatment as usual.

\section{Methods}

\section{Trial design}

The study was designed as a mixed-methods, two-arm, randomised feasibility trial including repeated prospective assessments: baseline, after 8 weeks, and follow-up after 16 weeks. The study was carried out in accordance with the CONSORT Extension to Pilot and Feasibility Trials, and an additional file provides a completed checklist (See Additional file 1). Results of a qualitative investigation including participant experiences have been published elsewhere (20). The ClinicalTrials.gov identifier is NCT03409393. Full trial protocol (in Danish) can be requested by contacting the corresponding author (JM).

\section{Setting}

The study was conducted within specialised multidisciplinary outpatient treatment units, called OPUS teams, offering early intervention treatment to patients in Denmark 18-34 years of age with first-episode psychosis. OPUS is a well-documented intensive specialised treatment modality consisting of three core elements: 1) modified assertive community treatment, 2) family involvement, and 3) social skills training. The patient-case manager ratio should not exceed 11:1 (4).

\section{Population}

Inclusion criteria were 18-34 years of age with a recent International Classification of Diseases, 10th revision (ICD-10) diagnosis of F20F29 (i.e. schizophrenia, schizotypy and delusional disorder, and other non-organic psychotic disorders). To ensure that the patients' treatment was stabilised and to avoid interference with concurrent clinical trials, patients were required to have been enrolled in OPUS for at least six months, corresponding to a minimum of 24 consecutive weeks of treatment with antipsychotic medication based on individual clinical needs. In case patients had been enrolled in OPUS for less than 6 months, evaluation by the treating psychiatrist was required.

\section{Recruitment}

Recruitment target was set at 30 patients in three months (December 2017 to February 2018). Patients were recruited from three OPUS units in the greater Copenhagen area, Denmark. The recruitment period began 6 weeks prior to the baseline test. OPUS staff (i.e. case managers) where invited to a kick-off meeting including discussion of optimal recruitment procedures. During this meeting it was decided that each case manager should perform an initial screening (assessment) of patients' eligibility and motivation, and that this assessment should be performed together with the patient. To support the OPUS staff, an assessment manual was developed, and one member of the research team was allocated an office desk in the building and participated actively in the recruitment during the entire period. Patients who were deemed eligible by OPUS case managers were invited to an individual information meeting with a member of the project staff, at which point they received a detailed oral and written description of the study, including additional and final screening. After informed written consent was obtained, patients were invited to baseline assessment prior to randomisation.

\section{Randomisation}

Immediately after baseline assessment, included patients were randomly assigned 1:1 to either the exercise intervention group (INT) or a control group (CON). Randomisation was based on a randomisation list generated by an external collaborator in STATA 15.1. Based on this list, 30 numbered, closed, and opaque envelopes were stored and managed by a different external collaborator, who performed the randomisation. A research assistant who assisted with scheduling orally told the study participants on site about the result of the randomisation. Given the nature of the intervention it was not possible to blind personnel or participants to the group assignment; however, the data manager/statistical consultant did not participate in the outcome assessment or data entry.

\section{Intervention}

The intervention consisted of 8 weeks of supervised group-based, multifaceted exercise training for one hour three times a week (twice a week at 11-12 am and once a week at 2-3 pm), with included patients recommended to take part in at least two sessions per week. The training sessions were inspired by CrossFit ${ }^{\circledR}$ and comprised of warm-up exercises followed by one or two playful, physically demanding games (e.g. dodgeball) and the workout of the day, typically consisting of circuit training. Participants were encouraged to suggest exercises and type of music or specific songs to be played. Sessions concluded with stretching exercises and, once a week, participants 
were invited to small talk and refreshments consisting of fruit and juice (free of charge). The intensity and complexity of the exercises was increased gradually to prevent injuries. The sessions, which took place at a fitness centre three kilometres away from the OPUS facility, were supervised by a trained physiotherapist and exercise physiologist, supported by undergraduate students from the University of Copenhagen Department of Nutrition, Exercise and Sports.

To support adherence, short text messages were sent to each participant the day before each training session, encouraging participants to show up. Furthermore, a Facebook $\circledast$ group for the participants was established to share information on the intervention. Participants were also offered free of charge participation in Copenhagen Warrior (www.copenhagenwarrior.dk) on 16 June 2018, a six-kilometre obstacle race with approximately 30 obstacles, to mark completion of the trial and provide an end goal.

\section{Control group}

All participants received treatment as usual. Patients allocated to CON were encouraged to continue normal physical activity. After 8 weeks (i.e. after participation in the 8-week follow-up), participants were offered the intervention, including an invitation to participate in the obstacle race.

\section{Outcome measures}

\section{Primary outcomes}

Screening rate was defined as the number of patients who had undergone OPUS treatment for a minimum of six months divided by the number of patients who were screened for eligibility by OPUS staff. Recruitment rate was defined as the number of patients screened by OPUS staff divided by the number of patients who consented to take part in the study. Retention rate was defined as the number of participants who remained in the study, i.e. the number of participants who did not drop out of the study. Adherence to the intervention was measured by calculating the sum of exercise sessions attended by each participant divided by the total number of exercise sessions. Cardiorespiratory fitness $\left(\mathrm{VO}_{2 \max }\right)$ was estimated using a direct determination of maximum oxygen uptake, following recognised standards.(21) The tests were carried out on a Monark ergometer bike (Monark Exercise, Vansbro, Sweden), and a breath-by-breath respiratory gas analysis (COSMED CPET, Cosmed, Rome, Italy) during both tests was used to take measurements.

\section{Secondary outcomes}

Body composition, including fat percentage and muscle mass, was assessed by means of the Inbody 570 bioelectric impedance scale (Inbody Co., Ltd. Seoul, Korea). Muscle strength included assessment of a 30-second sit-to-stand chair test, hand grip strength by means of a digital hydraulic dynamometer (NexGen Ergonomics Inc., Quebec, Canada) (22) and measurement of vertical jump height using the OPTOJUMP modular system (MICROGATE, Bolzano-Bozen, Italy) (23). Balance was measured by means of a single-leg flamingo balance test (24). Resting heart rate and blood pressure were measured according to the American Heart Association guidelines for blood pressure measurement (25). Blood pressure and resting heart rate were measured three times at 30 seconds intervals. The average of the three measurements was used as the test result.

\section{Other outcomes}

Adverse events were classified according to Good Clinical Practice definitions and recorded prospectively and as related or unrelated to the study. Heart rate response during training was assessed for the intervention group in the first 8 weeks using ActiGraph wGT3x+ (ACTIGRAPH, Pensacola, Florida, USA) activity monitors.

\section{Sample size estimation}

Since the primary aim of the current study was to establish feasibility, no a priori power calculation was performed to determine statistical power to detect between-group differences.

\section{Data management and analysis}

Study data were collected and managed using Research Electronic Data Capture (REDCap) electronic data capture tools hosted at the Centre for IT, Medical Technology and Telephony Services/Capital Region of Denmark. REDCap is a secure, web-based application designed to support data capture for research studies (26). The statistical analyses were performed using STATA version 15.1. In accordance with the updated CONSORT guidelines for pilot and feasibility studies (27) analyses were descriptive. Outcomes were assessed using standard methods for rates, proportions, percentages, and sample means. Means and $95 \%$ confidence intervals (Cl) are reported for secondary outcomes at baseline and the 8-week and 16-week follow-ups for each group. Participants were analysed as part of the group they were allocated to regardless of post-randomisation exercise behaviour. 


\section{Results}

\section{Patient characteristics}

There were 19 female and 6 male patients with early psychosis (mean age $=25.6$ years, SD $=4.5$, range $=18-35$ ) and a mean body mass index of $25(S D=5$, range $=18-39)$. Table 1 lists additional characteristics of included patients.

Table 1

Demographic and medical characteristics of included patients

\begin{tabular}{|c|c|c|}
\hline Variable & $\begin{array}{l}\text { COPUS group } \\
(n=13)\end{array}$ & $\begin{array}{l}\text { Control group } \\
(n=12)\end{array}$ \\
\hline Age (years) & $23,8(4,5)$ & $27,5(4,5)$ \\
\hline Sex, Female n (\%) & $9(69 \%)$ & $10(83 \%)$ \\
\hline Weight, (kg) & $80,3(18,5)$ & $67,0(16,1)$ \\
\hline Height, (cm) & $174,4(8,9)$ & $167,2(9,0)$ \\
\hline Body Mass Index $\left(\mathrm{kg} / \mathrm{m}^{2}\right)$ & $26,4(5,7)$ & $23,7(21,3)$ \\
\hline Diagnosis & 7 & 5 \\
\hline F20 schizophrenia & 5 & 5 \\
\hline F21 schizotypal & 1 & 2 \\
\hline \multicolumn{3}{|l|}{ F29 non-organic psychoses } \\
\hline Self-reported physical activity* & 2 & 4 \\
\hline Almost completely inactive & 6 & 5 \\
\hline Moderate (2-4 hours a week) & 4 & 3 \\
\hline Moderate (4 hours a week) & 1 & 1 \\
\hline \multicolumn{3}{|l|}{ Strenuous ( $>4$ hours a week) } \\
\hline Regular smoking & 9 & 8 \\
\hline No & 4 & 4 \\
\hline \multicolumn{3}{|l|}{ Yes } \\
\hline Cannabis use & 8 & 8 \\
\hline Never tried & 4 & 2 \\
\hline Tried few times & 1 & 2 \\
\hline Regularly use & & \\
\hline
\end{tabular}

[Table 1. Demographic and medical characteristics of included patients]

\section{Primary outcomes}

The screening rate was $27 \%$ and the recruitment rate was $35 \%$. Specifically, 21 out of 30 OPUS case managers ( $70 \%$ of staff) performed screening of 86 out of the 324 patients receiving OPUS treatment. Out of the 86 patients that were screened, 49 (56\%) were screened by 5 case managers (17\% of staff). Fifteen (17\%) out of the 86 patients who were screened by OPUS case managers were subsequently excluded mainly due to time constraints or disease-related causes (i.e. symptom burden). In total, 71 out of the 86 (83\%) patients were deemed eligible to participate, of which $25(35 \%)$ agreed to inclusion and were randomly assigned to INT $(n=13)$ or CON $(n=12)$. Five participants $(38 \%)$ chose to discontinue before beginning the intervention or were lost to follow-up prior to completing the intervention. Retention at the 8-week follow-up was $76 \%$ and at 16 -weeks it was $52 \%$. Figure 1 illustrates patient flow during the study.

[Fig. 1. Flow of patients through the trial] 
Patients in INT who completed pre- and 8-week post-intervention assessments attended a mean of nine out of the 22 training sessions, corresponding to an attendance rate of 43\% (min. 9\%, max. 96\%). Six (46\%) and 11 (92\%) of patients allocated to INT and CON, respectively, agreed to exercise from week 8 to week 16 (attendance rate $35 \%$ for INT and $44 \%$ for CON). A total of 10 patients ( 5 from INT and 5 from $\mathrm{CON}$ ) completed the obstacle race, which took place two weeks after study completion. No changes were detected in either groups in cardiorespiratory fitness.

\section{Secondary outcomes}

Significant improvements were observed in INT in sit-to-stand from baseline to the 8-week follow-up (mean difference 2.8 repetitions, $95 \%$ $\mathrm{Cl} 0.4$ to 5.1 ) and in jump height from 8 weeks to 16 weeks (mean difference $1.6 \mathrm{~cm}, 95 \% \mathrm{Cl} 0.2$ to 2.9 ). In CON, significant improvements were observed in sit-to-stand from baseline to the 8-week follow-up (mean difference 1 repetition, $95 \% \mathrm{Cl} 0.3$ to 1.7 ) and from 8 weeks to 16 weeks (mean difference 1.7 repetitions, $95 \% \mathrm{Cl} 0.7$ to 2.7). Moreover, significant improvements were seen from week 8 to week 16 in $\mathrm{CON}$ in muscle mass (mean difference $0.8 \mathrm{~kg}, 95 \% \mathrm{Cl} 0.3$ to 1.4) and in jump height (mean difference $1.3 \mathrm{~cm}, 95 \% \mathrm{Cl} 0.1$ to 2.5 ). Table 2 lists means and $95 \%$ Cls on cardiorespiratory fitness and secondary outcomes measures. 
Table 2

Means and 95\% confidence interval on cardiorespiratory fitness and secondary outcome measures

\begin{tabular}{|c|c|c|c|c|c|c|c|c|c|c|}
\hline & $\begin{array}{l}\mathrm{VO}_{2} \max \\
(\mathrm{mL} / \mathrm{min})\end{array}$ & $\begin{array}{l}\text { Resting } \\
\text { heart } \\
\text { rate }\end{array}$ & $\begin{array}{l}\text { Diastolic } \\
\text { blood } \\
\text { pressure }\end{array}$ & $\begin{array}{l}\text { Systolic } \\
\text { blood } \\
\text { pressure }\end{array}$ & $\begin{array}{l}\text { Fat } \\
\text { percentage } \\
(\%)\end{array}$ & $\begin{array}{l}\text { Muscle } \\
\text { mass (kg) }\end{array}$ & $\begin{array}{l}\text { STS-30 } \\
\text { (repetitions) }\end{array}$ & $\begin{array}{l}\text { Grip } \\
\text { strength } \\
\text { (kg) }\end{array}$ & $\begin{array}{l}\text { Jump } \\
\text { height } \\
\text { (cm) }\end{array}$ & $\begin{array}{l}\text { Balance } \\
\text { test } \\
\text { (falls, } \\
\text { n) }\end{array}$ \\
\hline \multicolumn{11}{|c|}{ INTERVENTION GROUP } \\
\hline \multicolumn{11}{|c|}{ Baseline } \\
\hline Mean & 2823 & 75,2 & 77,1 & 118,7 & 29,1 & 31,2 & 18,4 & 35,2 & 20,4 & 16,9 \\
\hline $95 \% \mathrm{Cl}$ & $\begin{array}{l}2328 \text { to } \\
3318\end{array}$ & $\begin{array}{l}66,6 \text { to } \\
83,9\end{array}$ & $\begin{array}{l}72,9 \text { to } \\
81,3\end{array}$ & $\begin{array}{l}112,8 \text { to } \\
124,6\end{array}$ & $\begin{array}{l}22,7 \text { to } \\
35,5\end{array}$ & 26,3 to 31,7 & 16,3 to 20,4 & $\begin{array}{l}30,2 \text { to } \\
40,1\end{array}$ & $\begin{array}{l}15,6 \\
\text { to } \\
25,3\end{array}$ & $\begin{array}{l}12,9 \text { to } \\
20,9\end{array}$ \\
\hline \multicolumn{11}{|l|}{8 weeks } \\
\hline Mean & 2775 & 81,4 & 80,5 & 117,4 & 26,3 & 30,6 & 22,4 & 37,1 & 22,5 & 14,6 \\
\hline $95 \% \mathrm{Cl}$ & $\begin{array}{l}1755 \text { to } \\
3794\end{array}$ & $\begin{array}{l}64,0 \text { to } \\
98,7\end{array}$ & $\begin{array}{l}72,2 \text { to } \\
88,8\end{array}$ & $\begin{array}{l}105,7 \text { to } \\
129,1\end{array}$ & $\begin{array}{l}15,3 \text { to } \\
37,2\end{array}$ & $\begin{array}{l}24,6 \text { to } \\
36,6\end{array}$ & 18,6 to 26,2 & $\begin{array}{l}27,5 \text { to } \\
46,8\end{array}$ & $\begin{array}{l}16,7 \\
\text { to } \\
28,4\end{array}$ & $\begin{array}{l}10,6 \text { to } \\
18,6\end{array}$ \\
\hline \multicolumn{11}{|c|}{ Change between baseline and 8 weeks } \\
\hline $\begin{array}{l}\text { Mean } \\
\text { change }\end{array}$ & 183 & 8,1 & 1,8 & $-3,6$ & 1,2 & $-0,5$ & 2,8 & 1,4 & $-0,4$ & -2 \\
\hline $95 \% \mathrm{Cl}$ & $\begin{array}{l}-250 \text { to } \\
617\end{array}$ & $\begin{array}{l}-10,8 \text { to } \\
27,0\end{array}$ & $\begin{array}{l}-3,3 \text { to } \\
6,8\end{array}$ & $\begin{array}{l}-12,0 \text { to } \\
4,7\end{array}$ & $-1,2$ to 3,7 & $-2,4$ to 1,4 & 0,4 to 5,1 & $\begin{array}{l}-2,3 \text { to } \\
5,0\end{array}$ & $\begin{array}{l}-2,3 \text { to } \\
1,5\end{array}$ & $\begin{array}{l}-6,5 \text { to } \\
2,5\end{array}$ \\
\hline \multicolumn{11}{|l|}{$\begin{array}{l}16 \\
\text { weeks }\end{array}$} \\
\hline Mean & 3110 & 80 & 74,2 & 123,5 & 22,8 & 29,2 & 22,5 & 32,8 & 25 & 12,3 \\
\hline $95 \% \mathrm{Cl}$ & $\begin{array}{l}1550 \text { to } \\
4670\end{array}$ & $\begin{array}{l}68,9 \text { to } \\
91,1\end{array}$ & $\begin{array}{l}64,0 \text { to } \\
84,3\end{array}$ & $\begin{array}{l}112,9 \text { to } \\
134,1\end{array}$ & 9,6 to 36,1 & $\begin{array}{l}20,8 \text { to } \\
37,6\end{array}$ & 19,5 to 25,5 & $\begin{array}{l}24,7 \text { to } \\
41,0\end{array}$ & $\begin{array}{l}17,1 \\
\text { to } \\
32,8\end{array}$ & $\begin{array}{l}7,0 \text { to } \\
17,7\end{array}$ \\
\hline \multicolumn{11}{|c|}{ Change between 8 weeks and 16 weeks } \\
\hline $\begin{array}{l}\text { Mean } \\
\text { change }\end{array}$ & 232 & 2,5 & $-2,5$ & 10,2 & $-0,4$ & 0,5 & $-0,2$ & $-1,2$ & 1,6 & $-0,8$ \\
\hline $95 \% \mathrm{Cl}$ & $\begin{array}{l}-1531 \text { to } \\
1996\end{array}$ & $\begin{array}{l}-17,0 \text { to } \\
22,0\end{array}$ & $\begin{array}{l}-7,6 \text { to } \\
2,6\end{array}$ & $\begin{array}{l}-2,2 \text { to } \\
22,6\end{array}$ & $-2,8$ to 2,0 & $-0,2$ to 1,2 & $-3,9$ to 3,6 & $\begin{array}{l}-6,8 \text { to } \\
4,4\end{array}$ & $\begin{array}{l}0,2 \text { to } \\
2,9\end{array}$ & $\begin{array}{l}-5,2 \text { to } \\
3,5\end{array}$ \\
\hline \multicolumn{11}{|c|}{ WAIT-LIST CONTROL GROUP } \\
\hline \multicolumn{11}{|c|}{ Baseline } \\
\hline Mean & 2315 & 78,8 & 78,4 & 113,9 & 27,3 & 26,6 & 16,3 & 32,8 & 19 & 15,7 \\
\hline $95 \% \mathrm{Cl}$ & $\begin{array}{l}1790 \text { to } \\
2839\end{array}$ & $\begin{array}{l}68,3 \text { to } \\
89,2\end{array}$ & $\begin{array}{l}74,2 \text { to } \\
82,7\end{array}$ & $\begin{array}{l}107,7 \text { to } \\
120,1\end{array}$ & $\begin{array}{l}22,7 \text { to } \\
31,8\end{array}$ & $\begin{array}{l}23,0 \text { to } \\
30,3\end{array}$ & 14,4 to 18,1 & $\begin{array}{l}29,0 \text { to } \\
36,5\end{array}$ & $\begin{array}{l}15,4 \\
\text { to } \\
22,7\end{array}$ & $\begin{array}{l}11,6 \text { to } \\
19,7\end{array}$ \\
\hline \multicolumn{11}{|c|}{8 weeks } \\
\hline Mean & 2399 & 81,4 & 77,8 & 113,1 & 26 & 26,5 & 17,3 & 34,6 & 19,3 & 15 \\
\hline $95 \% \mathrm{Cl}$ & $\begin{array}{l}1719 \text { to } \\
3080\end{array}$ & $\begin{array}{l}70,6 \text { to } \\
92,1\end{array}$ & $\begin{array}{l}73,3 \text { to } \\
82,4\end{array}$ & $\begin{array}{l}106,1 \text { to } \\
120,0\end{array}$ & $\begin{array}{l}20,5 \text { to } \\
31,4\end{array}$ & $22,131,0$ & 15,1 to 19,4 & $\begin{array}{l}29,3 \text { to } \\
40,0\end{array}$ & $\begin{array}{l}15,8 \\
\text { to } \\
22,9\end{array}$ & $\begin{array}{l}11,5 \text { to } \\
18,5\end{array}$ \\
\hline
\end{tabular}

Change between baseline and 8 weeks

\begin{tabular}{|c|c|c|c|c|c|c|c|c|c|c|}
\hline Mean change & 11 & 2,1 & $-0,8$ & $-1,5$ & $-0,5$ & $-0,2$ & 1 & 1,6 & 0,5 & $-0,6$ \\
\hline $95 \% \mathrm{Cl}$ & $\begin{array}{l}-106 \text { to } \\
127\end{array}$ & $\begin{array}{l}-8,0 \text { to } \\
12,2\end{array}$ & $\begin{array}{l}-4,7 \\
\text { to } \\
3,0\end{array}$ & $\begin{array}{l}-7,2 \text { to } \\
4,1\end{array}$ & $-2,7$ to 1,7 & $\begin{array}{l}-0,9 \\
\text { to } \\
0,6\end{array}$ & 0,3 to 1,7 & $\begin{array}{l}-0,6 \\
\text { to } \\
3,9\end{array}$ & $\begin{array}{l}-1 \text { to } \\
1,1\end{array}$ & $-4,5$ to 3,2 \\
\hline
\end{tabular}




\begin{tabular}{|c|c|c|c|c|c|c|c|c|c|c|c|c|}
\hline $\begin{array}{l}\mathrm{VO}_{2} \mathrm{max} \\
(\mathrm{mL} / \mathrm{min})\end{array}$ & $\begin{array}{l}\text { Resting } \\
\text { heart } \\
\text { rate }\end{array}$ & $\begin{array}{l}\text { Diastolic } \\
\text { blood } \\
\text { pressure }\end{array}$ & \multicolumn{2}{|c|}{$\begin{array}{l}\text { Systolic } \\
\text { blood } \\
\text { pressure }\end{array}$} & $\begin{array}{l}\text { Fat } \\
\text { percentage } \\
(\%)\end{array}$ & \multicolumn{2}{|c|}{$\begin{array}{l}\text { Muscle } \\
\text { mass (kg) }\end{array}$} & $\begin{array}{l}\text { STS-30 } \\
\text { (repetitions) }\end{array}$ & \multicolumn{2}{|c|}{$\begin{array}{l}\text { Grip } \\
\text { strength } \\
\text { (kg) }\end{array}$} & $\begin{array}{l}\text { Jump } \\
\text { height } \\
\text { (cm) }\end{array}$ & $\begin{array}{l}\text { Balance } \\
\text { test } \\
\text { (falls, } \\
n \text { ) }\end{array}$ \\
\hline \multicolumn{13}{|l|}{16 weeks } \\
\hline Mean & 2234 & 73,9 & 69,3 & 115,7 & 25 & & 25,5 & 20 & 33,1 & 21,6 & 11 & \\
\hline $95 \% \mathrm{Cl}$ & $\begin{array}{l}1562 \\
\text { to } \\
2907\end{array}$ & $\begin{array}{l}61,6 \text { to } \\
86,1\end{array}$ & $\begin{array}{l}63,1 \\
\text { to } \\
75,5\end{array}$ & $\begin{array}{l}109,0 \\
\text { to } \\
122,4\end{array}$ & 15,6 to 3 & 34,5 & $\begin{array}{l}21,9 \\
29,2\end{array}$ & $\begin{array}{l}17,0 \text { to } \\
23,0\end{array}$ & $\begin{array}{l}27,4 \\
\text { to } \\
38,9\end{array}$ & $\begin{array}{l}16,0 \\
\text { to } \\
27,3\end{array}$ & & to 14,1 \\
\hline \multicolumn{13}{|c|}{ Change between 8 weeks and 16 weeks } \\
\hline Mean change & -4 & $-4,1$ & $-8,3$ & 5,7 & $-0,6$ & & 0,8 & 1,7 & $-0,7$ & 1,3 & -1 , & \\
\hline $95 \% \mathrm{Cl}$ & $\begin{array}{l}-328 \text { to } \\
320\end{array}$ & $\begin{array}{l}-13 \text { to } \\
4,7\end{array}$ & $\begin{array}{l}-13,1 \\
\text { to } \\
-3,5\end{array}$ & $\begin{array}{l}-1,0 \text { to } \\
12,4\end{array}$ & $-4,0$ to 3 , & & $\begin{array}{l}0,3 \\
\text { to } \\
1,4\end{array}$ & 0,7 to 2,7 & $\begin{array}{l}-2,4 \\
\text { to } \\
0,9\end{array}$ & $\begin{array}{l}0,1 \\
\text { to } \\
2,5\end{array}$ & & to 1,2 \\
\hline
\end{tabular}

[Table 2. Means and 95\% confidence interval on cardiorespiratory fitness and secondary outcome measures]

\section{Other outcomes}

During the assessment periods, one adverse event was registered and involved compulsory admission. The patient was assessed by the treating psychiatrist, who concluded that the event was unrelated to the intervention, and the patient was allowed to continue participation in the exercise training sessions. No other adverse events were reported during the study. The exercise training programme was performed at moderate intensity $41 \%$ of the time $\left(65-85 \% \mathrm{HR}_{\max }\right)$ and at high intensity $19 \%$ of the time $\left(85-100 \mathrm{HR}_{\max }\right)$.

\section{Discussion}

Despite early psychosis being proposed as the optimal phase for using exercise (12) the current study is among the first randomised controlled trial to assess feasibility of an exercise training program, compared to usual care in patients with first-episode psychosis undergoing specialised early intervention.

Our primary feasibility outcomes (screening and recruitment rates) indicate that our study set-up did not provide sufficient incentives and/or infrastructure to ensure consecutive screening and systematic promotion by the case managers and psychiatrists in charge of medical treatment. Despite a successful kick-off meeting, positive initial feedback from OPUS case managers in terms of their central role in screening and recruitment, and continuous encouragement and practical help from members of the research teams, we did not reach our recruitment target of 30 patients. More than half of screened patients were screened by less than $20 \%$ of case managers. While the case load in OPUS is 1:11 (i.e. each case manager covers the treatment of 11 patients), only 5 case managers (i.e. $17 \%$ of staff) screened more than 7 patients, whereas 14 (i.e. $47 \%$ of staff) screened three patients each or less. While staff motivation for active involvement in recruitment of patients remains unexplored in the current study, a recent qualitative study suggests an uncertainty among nurses concerning the benefits of physical activity as complementary treatment in patients with schizophrenia, indicating that hidden resistance exists in terms of the whole concept (28). Moreover, a recent study (29) indicated that exposing mental health staff to lifestyle interventions prior to targeting patients is critical in instigating culture change and improving patient outcomes. As such, closer collaboration with staff, including shared ownership and potentially staff-focused interventions, appear warranted to support recruitment of study participants in future exercise trials. Consequently, subsequent to trial completion, we invited participants and OPUS staff to an evaluation meeting, which resulted in the following additional suggestions for improved screening, recruitment, and retention rates in future trials: provide a trial exercise session to staff and potential participants, involve peers as part of recruitment strategy, focus on implementation of strategies for sustainment of exercise post-intervention, have flexible exercise schedules, and provide the option of choosing low intensity/relaxation exercises on days with high symptom burden/anxiety.

In this trial, secondary outcomes were selected based on the assumption that participants' physical health would undergo measurable improvements attributable to our intervention. However, because the current trial was not designed or statistically powered to test for differences between treatment arms, no between-group analyses were performed, and the relatively small number of randomised patients and the large variation in outcomes make it impossible to derive an obvious candidate as the primary outcome for a large-scale randomised controlled trial based on the results from this feasibility trial. However, statistically significant within-group changes observed in sit-to-stand in INT from 0-8 weeks and in CON from 8-16 weeks suggest that the intervention may have had an impact on participants' functional capacity, whereas no changes were observed in fitness, which may be related to the limited training frequency and the fact that 
only $19 \%$ of the intervention was performed at high intensity. Also, because participants had been on antipsychotic treatment for a minimum of 24 weeks ahead of enrolment, it is possible that metabolic changes had already installed, and that earlier initiation of exercise (i.e. before or concurrent with initiation of antipsychotic medication) would have been preferable. For example, attenuation of expected decreased fitness and prevention of weight gain, for which patients with first-episode psychosis are particularly susceptible, may be relevant candidates (30). As such, it should also be considered whether a more realistic goal besides improvements in physiological and functional outcomes should be chosen. Moreover, it is worth considering whether simultaneously targeting multiple lifestyle factors (i.e. poor diet and smoking) instead of focusing on one behavioural modification, i.e. increasing physical exercise, may be more appropriate as suggested by The Lancet Psychiatry Commission (11). Yet, the perceived changes in some outcomes (and the lack of changes in other others) in the current study should be interpreted with great caution and should not be ascribed a positive physiological effect (or the opposite). Furthermore, it is possible that the measures of mental health outcomes that are typically used in psychiatric treatment intervention studies may be equally relevant to physiological endpoints in a future large-scale trial. While subjective outcomes were not included in the current trial due to an expected lack of statistical power, our recently published qualitative sub-study (20) suggested that those who were included in the trial appreciated the intervention because of its potential to create an environment that was equally challenging and caring. Some participants also described the intervention as providing a relieving distraction from symptoms, while some reported improved sleep (20). This indicates that outcomes specifically related to self-efficacy and/or psychosocial well-being (i.e. stigmatisation, recovery, sleep quality, and loneliness) may be especially relevant to include in our future work.

\section{Conclusions}

In conclusion the current study elucidated operational factors in relation to feasibility in terms of applying a randomised controlled trial design to allow for a rigorous evaluation of effects of exercise training in patients with first-episode psychosis. These elements are considered in the design of a future trial, where we plan to use a multi-centre, pragmatic clinical trial design to examine the effectiveness of exercise training in a non-clinical setting as potentially promoting sustainability. This trial will also include an educational programme targeting mental health professionals involved in recruitment. As future endpoints, more patient-related measures, rather than a strict focus on objective physiological measures may prove relevant.

\section{Abbreviations}

FEP

First-episode psychosis

INT

Intervention group

CON

Control group

ICD-10

International Classification of Diseases, 10th revision

REDCap

Research Electronic Data Capture

\section{Declarations}

\section{Ethics approval and consent to participate}

The Danish Data Protection Agency (file no.: 2012-58-0004) and the National Committee on Health Research Ethics (H-17018798) approved all study activities.

\section{Consent for publication}

"Not applicable".

\section{Availability of data and materials}

The datasets used and/or analysed during the current study are available from the corresponding author on reasonable request. 
Dr. Ebdrup is part of Advisory Boards of Eli Lilly Denmark A/S, Janssen-Cilag, Lundbeck Pharma A/S, and Takeda Pharmaceutical Company Ltd; and has received lecture fees from Boehringer Ingelheim Danmark A/S, Bristol-Myers Squibb, Otsuka Pharma Scandinavia AB, Eli Lilly Company, and Lundbeck Pharma A/S.

\section{Funding}

This work was supported by TrygFonden under Grant 119481.

\section{Authors' contributions}

JM led the team and drafted this article; JM, TJ, and NBN drafted the protocol prior to the funding application; JM and HS prepared the protocol and ethics application; EB provided statistical and methodological expertise and led the analysis; TJ, NJ, SS, NF, and JR delivered the intervention and collected data; BHE provided psychiatric treatment expertise; and NBN provided test equipment and training expertise, including recruitment and supervision of students in charge of intervention delivery. All authors approved and commented on the manuscript.

\section{Acknowledgements}

The authors gratefully acknowledge Helene Speyer for valuable inputs in the planning phase of the trial, and Janni Enghave Andersen for participating in the execution of the trial.

\section{References}

1. Loranger AW. Sex difference in age at onset of schizophrenia. Archives of general psychiatry. 1984;41(2):157-61.

2. Immonen J, Jaaskelainen E, Korpela H, Miettunen J. Age at onset and the outcomes of schizophrenia: A systematic review and metaanalysis. Early intervention in psychiatry. 2017;11(6):453-60.

3. Nordentoft M, Rasmussen JO, Melau M, Hjorthoj CR, Thorup AA. How successful are first episode programs? A review of the evidence for specialized assertive early intervention. Current opinion in psychiatry. 2014;27(3):167-72.

4. Albert N, Melau M, Jensen H, Emborg C, Jepsen JR, Fagerlund B, et al. Five years of specialised early intervention versus two years of specialised early intervention followed by three years of standard treatment for patients with a first episode psychosis: randomised, superiority, parallel group trial in Denmark (OPUS II). Bmj. 2017;356:i6681.

5. Marshall M, Rathbone J. Early intervention for psychosis. Cochrane Database Syst Rev. 2011(6):Cd004718.

6. Schmitt A, Maurus I, Rossner MJ, Roh A, Lembeck M, von Wilmsdorff M, et al. Effects of Aerobic Exercise on Metabolic Syndrome, Cardiorespiratory Fitness, and Symptoms in Schizophrenia Include Decreased Mortality. Frontiers in psychiatry. 2018;9:690.

7. Laursen TM, Munk-Olsen T, Nordentoft M, Mortensen PB. Increased mortality among patients admitted with major psychiatric disorders: a register-based study comparing mortality in unipolar depressive disorder, bipolar affective disorder, schizoaffective disorder, and schizophrenia. The Journal of clinical psychiatry. 2007;68(6):899-907.

8. Wahlbeck K, Westman J, Nordentoft M, Gissler M, Laursen TM. Outcomes of Nordic mental health systems: life expectancy of patients with mental disorders. Br J Psychiatry. 2011;199(6):453-8.

9. Hjorthoj C, Sturup AE, McGrath JJ, Nordentoft M. Years of potential life lost and life expectancy in schizophrenia: a systematic review and meta-analysis. The lancet Psychiatry. 2017;4(4):295-301.

10. Oakley P, Kisely S, Baxter A, Harris M, Desoe J, Dziouba A, et al. Increased mortality among people with schizophrenia and other nonaffective psychotic disorders in the community: A systematic review and meta-analysis. Journal of psychiatric research. 2018;102:245-53.

11. Firth J, Siddiqi N, Koyanagi A, Siskind D, Rosenbaum S, Galletly C, et al. The Lancet Psychiatry Commission: a blueprint for protecting physical health in people with mental illness. The lancet Psychiatry. 2019;6(8):675-712.

12. Firth J, Cotter J, Elliott R, French P, Yung AR. A systematic review and meta-analysis of exercise interventions in schizophrenia patients. Psychological medicine. 2015;45(7):1343-61.

13. McNamee L, Mead G, MacGillivray S, Lawrie SM. Schizophrenia, poor physical health and physical activity: evidence-based interventions are required to reduce major health inequalities. Br J Psychiatry. 2013;203(3):239-41.

14. Nielsen MO, Rostrup E, Wulff S, Glenthoj B, Ebdrup BH. Striatal Reward Activity and Antipsychotic-Associated Weight Change in Patients With Schizophrenia Undergoing Initial Treatment. JAMA psychiatry. 2016;73(2):121-8. 
15. Rummel-Kluge C, Komossa K, Schwarz S, Hunger H, Schmid F, Lobos CA, et al. Head-to-head comparisons of metabolic side effects of second generation antipsychotics in the treatment of schizophrenia: a systematic review and meta-analysis. Schizophrenia research. 2010;123(2-3):225-33.

16. Allison DB, Mentore JL, Heo M, Chandler LP, Cappelleri JC, Infante MC, et al. Antipsychotic-induced weight gain: a comprehensive research synthesis. The American journal of psychiatry. 1999;156(11):1686-96.

17. Abdel-Baki A, Brazzini-Poisson V, Marois F, Letendre E, Karelis AD. Effects of aerobic interval training on metabolic complications and cardiorespiratory fitness in young adults with psychotic disorders: a pilot study. Schizophrenia research. 2013;149(1-3):112-5.

18. Firth J, Carney R, Elliott R, French P, Parker S, Mclntyre R, et al. Exercise as an intervention for first-episode psychosis: a feasibility study. Early intervention in psychiatry. 2018;12(3):307-15.

19. Curtis J, Watkins A, Rosenbaum S, Teasdale S, Kalucy M, Samaras K, et al. Evaluating an individualized lifestyle and life skills intervention to prevent antipsychotic-induced weight gain in first-episode psychosis. Early intervention in psychiatry. 2016;10(3):26776.

20. Larsen LQ, Schnor H, Tersbol BP, Ebdrup BH, Nordsborg NB, Midtgaard J. The impact of exercise training complementary to early intervention in patients with first-episode psychosis: a qualitative sub-study from a randomized controlled feasibility trial. BMC psychiatry. 2019;19(1):192.

21. American Thoracic S, American College of Chest P. ATS/ACCP Statement on cardiopulmonary exercise testing. Am J Respir Crit Care Med. 2003;167(2):211-77.

22. Gunther CM, Burger A, Rickert M, Crispin A, Schulz CU. Grip strength in healthy caucasian adults: reference values. J Hand Surg Am. 2008;33(4):558-65.

23. Attia A, Dhahbi W, Chaouachi A, Padulo J, Wong D, Chamari K. Measurement errors when estimating the vertical jump height with flight time using photocell devices: the example of Optojump. Biol Sport. 2016;34(1):63-70.

24. Deforche B, Lefevre J, De Bourdeaudhuij I, Hills AP, Duquet W, Bouckaert J. Physical fitness and physical activity in obese and nonobese Flemish youth. Obes Res. 2003;11(3):434-41.

25. Pickering TG, Hall JE, Appel LJ, Falkner BE, Graves J, Hill MN, et al. Recommendations for blood pressure measurement in humans and experimental animals: part 1: blood pressure measurement in humans: a statement for professionals from the Subcommittee of Professional and Public Education of the American Heart Association Council on High Blood Pressure Research. Circulation. 2005;111(5):697-716.

26. Harris PA, Taylor R, Thielke R, Payne J, Gonzalez N, Conde JG. Research electronic data capture (REDCap)-a metadata-driven methodology and workflow process for providing translational research informatics support. J Biomed Inform. 2009;42(2):377-81.

27. Eldridge SM, Chan CL, Campbell MJ, Bond CM, Hopewell S, Thabane L, et al. CONSORT 2010 statement: extension to randomised pilot and feasibility trials. Bmj. 2016;355:i5239.

28. Carlbo A, Claesson HP, Astrom S. Nurses' Experiences in using Physical Activity as Complementary Treatment in Patients with Schizophrenia. Issues in mental health nursing. 2018;39(7):600-7.

29. Rosenbaum S, Ward PB, Baldeo R, Fibbins H, Jarman R, Lederman O, et al. Changing health workforce attitudes to promote improved physical health in mental health service users: Keeping our Staff in Mind (KoSiM). Health Promot J Austr. 2020;31(3):447-55.

30. Alvarez-Jimenez M, Hetrick SE, Gonzalez-Blanch C, Gleeson JF, McGorry PD. Non-pharmacological management of antipsychoticinduced weight gain: systematic review and meta-analysis of randomised controlled trials. Br J Psychiatry. 2008;193(2):101-7.

31. Rödjer L, Jonsdottir IH, Rosengren A, Björck L, Grimby G, Thelle DS, et al. Self-reported leisure time physical activity: a useful assessment tool in everyday health care. BMC public health. 2012;12:693-

\section{Figures}




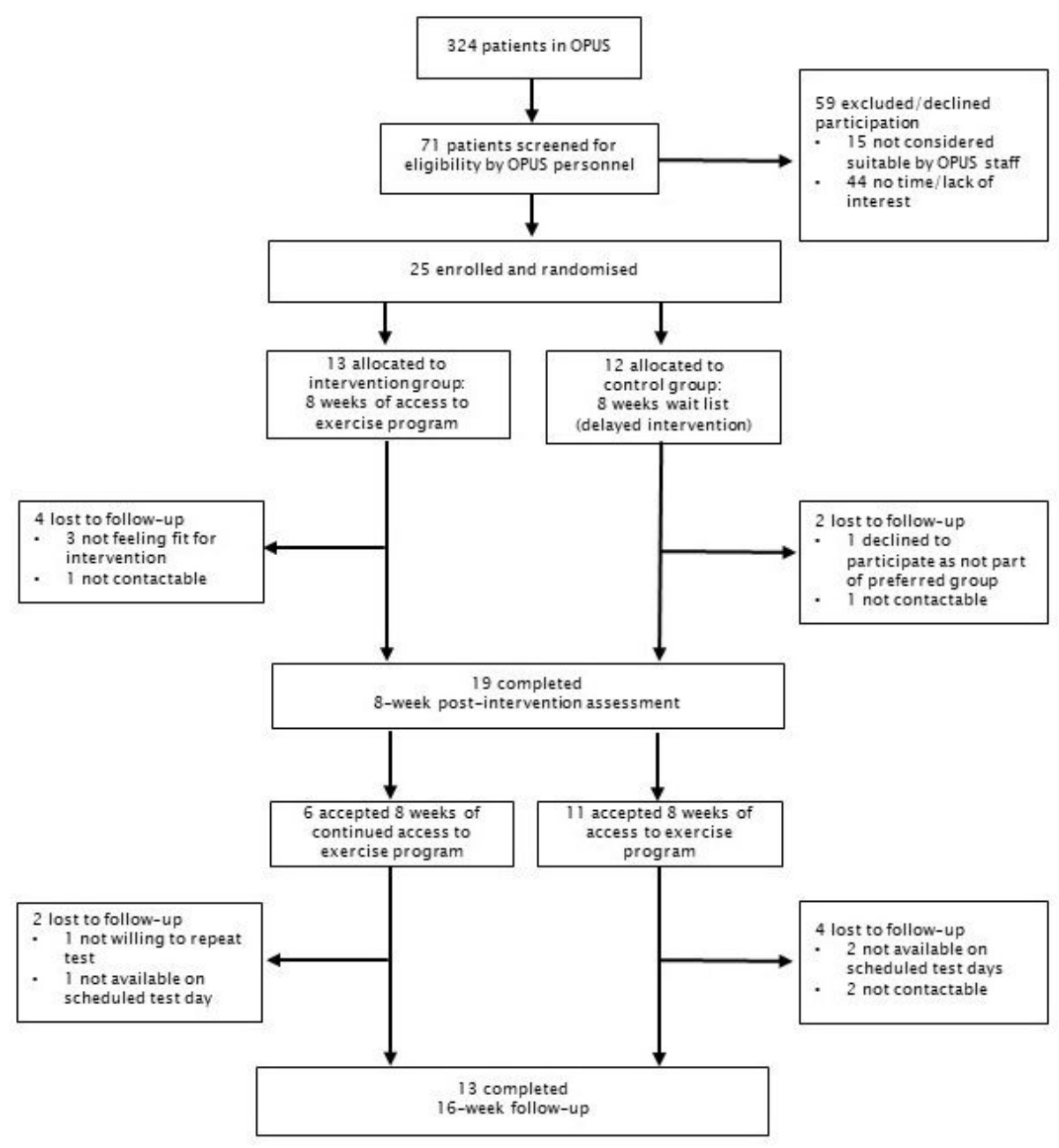

Figure 1

illustrates patient flow during the study

\section{Supplementary Files}

This is a list of supplementary files associated with this preprint. Click to download.

- CONSORTChecklistcompleted.pdf 